\title{
COMBINED GROUND LEVEL AND SATELLITE MONITORING OF URBAN AIR POLLUTION, ESTIMATION OF THE NUMBER OF PATIENTS TREATED IN HOSPITALS DUE TO AIR POLLUTION AND THE COST OF THEIR TREATMENT - CASE STUDY OF RUSE, BULGARIA
}

\author{
N. Takuchev ${ }^{1 *}$, P. Kostadinova ${ }^{2}$, G. Naydenova ${ }^{3}$, I. Stoilova ${ }^{3}$ \\ ${ }^{1}$ Trakia University, Agrarian Faculty, Department of Biochemistry, microbiology and physics, Stara \\ Zagora, Bulgaria \\ ${ }^{2}$ Regional Health Insurance Fund - Pleven, Bulgaria \\ ${ }^{3}$ Medical University, Pleven, Bulgaria
}

\begin{abstract}
INTRODUCTION. The city of Ruse has often suffered from air pollutions. The PURPOSE of the study is to estimate both the patients' number in the hospitals of Ruse district due to air pollution and the cost of their treatment. METHODS. The correlation and regression analyzes were used to study the dependencies between the meteorological parameters and the concentrations of air pollutants (obtained by the combination of ground level and satellite monitoring) and the annual number of patients treated in Ruse district hospitals, separated in clinical pathways. The correlation method was used to detect a link between pollutants and clinical pathway morbidity, and the regression method was used to assess the share of patients due to the air pollution. RESULTS. Statistically significant positive correlations were found between the investigated air pollutants and the annual number of the Ruse patients in 73 of the 125 clinical pathways studied. The pollutant with the greatest impact on health, estimated by the number of patients treated in the hospital, was the methane in the ground level air of Ruse, often in combination with benzene and fine particulate matter. Of the air pollutants over Ruse have been affected $15 \%$ of the patients treated on clinical pathways and for their treatment spent $17 \%$ of the public funds for hospital treatment in Ruse district.
\end{abstract}

Key words: Urban air pollution, morbidity, clinical pathways, air quality, air pollutants, satellite monitoring, ground-level monitoring

\section{INTRODUCTION}

In recent years the population of a number of large cities in Bulgaria has often expressed a civil protest in relation to the failure of the responsible institutions to deal with the problem of polluted air. One of the bigger cities with problems with air quality is Ruse $\left(43^{\circ} 49^{\prime} 23^{\prime \prime} \mathrm{N}, \quad 25^{\circ} 57^{\prime} 14 " \mathrm{E}, \quad(1)\right)$ with a population of 145,765 inhabitants according to the National Statistical Institute (NSI) to 31.12.2015 (2).

The aim of the exposed below study was to clarify the extent to which citizens of Ruse have reason to worry about a potential health deterioration caused by the polluted air above

\footnotetext{
*Correspondence to: Nikolay Takuchev, ${ }^{\text {I Trakia }}$

University, Agrarian Faculty, Department of Biochemistry, microbiology and physics, Stara Zagora,Bulgaria,npt@uni-sz.bg
}

the city, and if such a deterioration is found, to clarify its extent as well as the public health expenditures, spent as a result of air pollution.

Ruse is a centre of a district. In Ruse district lives 3.29\% of the population of the Republic of Bulgaria (to 31.12.2009, (2)). The area is densely populated, with about $30 \%$ higher density than the country average. It was assumed in the study that due to the concentration of a large part of the population of the district in the city of Ruse $(60 \%)$, in a relatively small area with similar air pollution, to a large extent the data on the regional (district) morbidity (for which there is collected data over the years) actually represents urban morbidity in the city of Ruse (for which there is no collected data). And if there is a negative influence of the air pollution on the health status of Ruse inhabitants, it would affect the data on regional morbidity. 


\section{MATERIAL AND METHODS}

\section{Data}

From the National Health Insurance Fund ware obtained data for the annual number of patients on clinical paths for Ruse district for the interval 2006 - 2012. Considerations on the use of data for the number of hospitalized patients and their clinical pathways are two presumably, these are the most accurate diagnoses, and, at the same time, the clinical pathways have a cost through which public expenditure on treatment due to air pollution could be evaluated.

The National Executive Environmental Agency (EEA) supports the network of automatic air quality stations operating in the main cities of each district. The automatic stations continuously monitor the meteorological parameters and the concentrations of air pollutants. Records from the automatic stations, in particular for the city of Ruse, were obtained from the EEA. An automatic station of urban background type with coordinates $43^{\circ} 51.090$ 'N; $25^{\circ} 57.846$ 'E was established in the city of Ruse in 2005 . For the years 2006 - 2012 average annual values were calculated from the obtained hourly data. Twenty-two meteorological parameters and air pollutant concentrations measured and recorded by the automatic ground station in Ruse were included in the study. Among them are the concentrations of: nitrogen dioxide $\mathrm{NO}_{2}$, measured in $\mu \mathrm{g} / \mathrm{m}^{3}$, sulfur dioxide $\left(\mathrm{SO}_{2}\right)$ in $\mu \mathrm{g} / \mathrm{m}^{3}$, ozone $\left(\mathrm{O}_{3}\right)$ in $\mu \mathrm{g} / \mathrm{m}^{3}$, fine particulate matter with a $10 \mu \mathrm{m}$ aerodynamic diameter $\left(\mathrm{PM}_{10}\right)$ in $\mu \mathrm{g} / \mathrm{m}^{3}$, benzene $\left(\mathrm{C}_{6} \mathrm{H}_{6}\right.$, also known as benzol) in $\mu \mathrm{g} / \mathrm{m}^{3}$. The notions of the listed concentrations, used in the text below, are given in brackets.

From a NASA site (3) data on meteorological parameters and the concentrations of some air pollutants both time-averaged - hourly, daily and monthly, and spatial averaged over the area of Ruse (in a rectangle with coordinates of the corners $25.92^{\circ}, 43.81^{\circ}, 26.03^{\circ}, 43.89^{\circ}$, covering the city of Ruse) were downloaded. Site data is a summary of satellite observations, ground observations, and numerical models developed on their basis.

Satellite measurements are continuous measurements in the surface band under the satellite. The satellite flies in a polar orbit (over the two poles) at hundreds of kilometres above the surface, constantly shifting, covering the whole surface of Earth (4). For example, Terra (5), on which board the instrument MOPITT (Measurements of Pollution in the Troposphere) is mounted, has circularly polar
TAKUCHEV N., et al. orbit at a height of $705 \mathrm{~km}$, makes a tour around the Earth in 99 minutes, shifts westward and passes over any point of the Earth's surface twice a day, at the same time of day and night, crossing the equator north to $10^{\mathrm{h}} 30^{\mathrm{m}}$ and south to $22^{\mathrm{h}} 30^{\mathrm{m}}$ local time (solarsynchronous polar orbit).

Due to the great height of the measuring instruments above the ground, meteorological parameters and pollution concentrations measured with satellites are averaged in the area, which is difficult to achieve with ground measurements but is appropriate in cases in which the impact of air pollutants over large areas as large cities or districts, is studied.

The data extracted from NASA's site included 20 meteorological parameters and concentrations of air pollutants. Among them are:

- Methane $\left(\mathrm{CH}_{4}\right)$ content in the ground air, characterized by the relative proportion (molar share) of methane molecules in the ground air, measured in ppbv (6);

- UV Aerosol Index (hereinafter referred to as Aerosol), a spectrometric parameter calculated from the absorption of ultraviolet radiation from solid particles into the air, characterizes the dust and soot content in the air, a dimensionless parameter (6);

- Sulfur dioxide $\left(\mathrm{SO}_{2}\right)$ and sulphate ion $\left(\mathrm{SO}_{4}\right)$, ground air concentration, in $\mathrm{kg} / \mathrm{m}^{3}(7)$;

- Ozone $\left(\mathrm{O}_{3}\right)$, total ozone content in the air column under the satellite in DU (Dobson Units), (8);

- Particulate matter (PM) and fine particulate matter $\left(\mathrm{PM}_{2,5}\right)$ ground air concentration in $\mathrm{kg} / \mathrm{m}^{3}$ (9);

- Black Carbon, ground air concentration in $\mathrm{kg} / \mathrm{m}^{3}(9)$;

- Carbon monoxide (CO), relative ground air concentration in ppbv (9).

In brackets are given the notations of the listed concentrations used in the text below. Satellite data ware also averaged over the year 20062012.

\section{Correlation analysis}

Data on the number of patients on clinical pathways and on air quality over Ruse were processed jointly by the statistical method of correlation analysis. The method produces a quantitative expression (correlation coefficient) of the degree of consistency in the variations of two sequences of numerical values, which are assumed to vary in the same proportions, i.e. that they are linearly dependent. Coherence can be expressed both in a coordinated increase and/or decrease of the 
TAKUCHEV N., et al.

two series (positive correlation) and in a concerted increase of one, combined with a decrease of the other and vice versa (negative, reverse correlation). The more coherent the changes of the two sets of numerical values, the more likely there is a causal relationship between them. In the absence of consistency between the changes in the two series, the correlation coefficient is zero. When there is complete consistency in the change of the two sets of numerical values, the correlation coefficient has a value of 1,000 for a positive correlation or $-1,000$ for a negative correlation. The closer the absolute value of the correlation coefficient is to 1,000 , the more strongly two sets of data are correlated.

The data series used in the study are the average annual values of meteorological parameters, air pollutant concentrations and the annual number of patients treated in a hospital on clinical pathways for the Rousse district. The series of data is 7 years long - from 2006 to 2012. Whether the number of patients treated on clinical pathways and air quality data should be expected to have a (linear) causal relationship was judged by the proximity of the correlation coefficient to a 1,000. Cases where is possible a nonlinear causal relationship has not been discussed in the study. Only positive correlation dependencies with coefficients around and above 0,9 are given below - i.e. those for which a strong positive causal relationship is expected - in which the number of patients treated on clinical pathways changes synchronously with the change in the concentration of air pollutant.

Is it possible to have a high positive correlation between a given meteorological parameter or concentration of the pollutant and the number of people treated on clinical pathways, while there is no causal relationship between them? Although such a hypothesis cannot be ruled out completely, according to the popular scientific principle known as "Occam's Razor", the simplest hypothesis is the most probable.
Therefore, it is most likely that there is a causal relationship in the cases with a high positive correlation.

The statistical parameter a statistical significance level characterizing the reliability of the correlation dependence was also determined. It shows the probability that the established correlation is due to accidental coincidence, without a causal link. The smaller this probability, the more reliable is the correlation between the two numerical ranges, the more likely it is to have a causal relationship between them. In the study described, correlations with a statistical significance of no more than 0.05 were taken as statistically significant.

Calculation of the proportion of patients treated on a clinical pathway as a result of air pollution and of public funds allocated for this treatment

Complex processes such as diseases are due to a multitude of causes, the polluted air being just one of the possible. The existence of a strong correlation between cause and effect does not mean the action of a single cause, but only the linearity of the causal relationship. The linear dependence is modelled by a linear regression model - a linear function between the characteristics of the cause (independent variable / independent variables) and the effect (dependent variable). These are, in this case, the concentration/concentrations of air pollutants and the number of patients treated on the clinical path.

A dependent variable in the regression models used was the number of patients treated on a clinical pathway as a function of the difference/differences in the annual concentration of the pollutant/pollutants with which this number had a positive, statistically significant correlation and its minimum in the annual concentrations.

The regression models used had the general appearance:

$$
\begin{gathered}
\text { Annual number of patients on a clinical path }= \\
=\text { intercept }+k_{1} *\left(C_{1}-C_{I \min }\right)+k_{2} *\left(C_{2}-C_{2 \min }\right)+k_{3} *\left(C_{3}-C_{3 \min }\right),
\end{gathered}
$$

where $\mathrm{k}_{1}, \mathrm{k}_{2}$ and $\mathrm{k}_{3}$ indicate the coefficients in front of the independent variables, with $\mathrm{C}_{1}, \mathrm{C}_{2}$ and $\mathrm{C}_{3}$ - the annual concentration of the respective pollutant, and with $\mathrm{C}_{1 \min }, \mathrm{C}_{2 \min }$ and $\mathrm{C}_{3 \min }$ - the respective minimum of the annual average concentrations for the years of study. Linear models with one, two or three variables were used in cases where the number of patients, treated on a given clinical pathway correlated positively and significantly with one, two or three pollutants.

If the minimum value of the independent variables in the regression model is zero, the intercept shows the number of patients not dependent on the variables included in the regression model. That is why the differences in the concentration of pollutants with their 
minimum value were used in the regression models for the independent variables. In this case, the intercept in the regression model is a function of all disease-causing impacts independent of the variables in the regression model - genetic, physiological, etc. Figure 1 shows the regression model of the dependence between the number of patients treated in the hospitals of a district Rousse on the "Infectious endocarditis" pathway and the average annual percentage of methane molecules in the air measured by satellite. The correlation coefficient $(0,994)$ between the two data series is statistically significant for the level of 0,001 . The regression line and the mathematical expression of the regression model, in this case, are also shown in the figure. The determination coefficient $\mathrm{R}^{2}$ determines the extent to which changes in annual pollutant concentrations in the model explain changes in the number of patients on a given clinical pathway. The maximum value 1,000 is reached when the change in the annual number of patients on the clinical pathway is fully explained by changes in the annual concentrations included in the model. In the example of Figure 1, the determination coefficient is 0,989 , which means that the methane content in the air almost completely determines the change in the number of patients with infectious endocarditis in Ruse region for the years of the study.

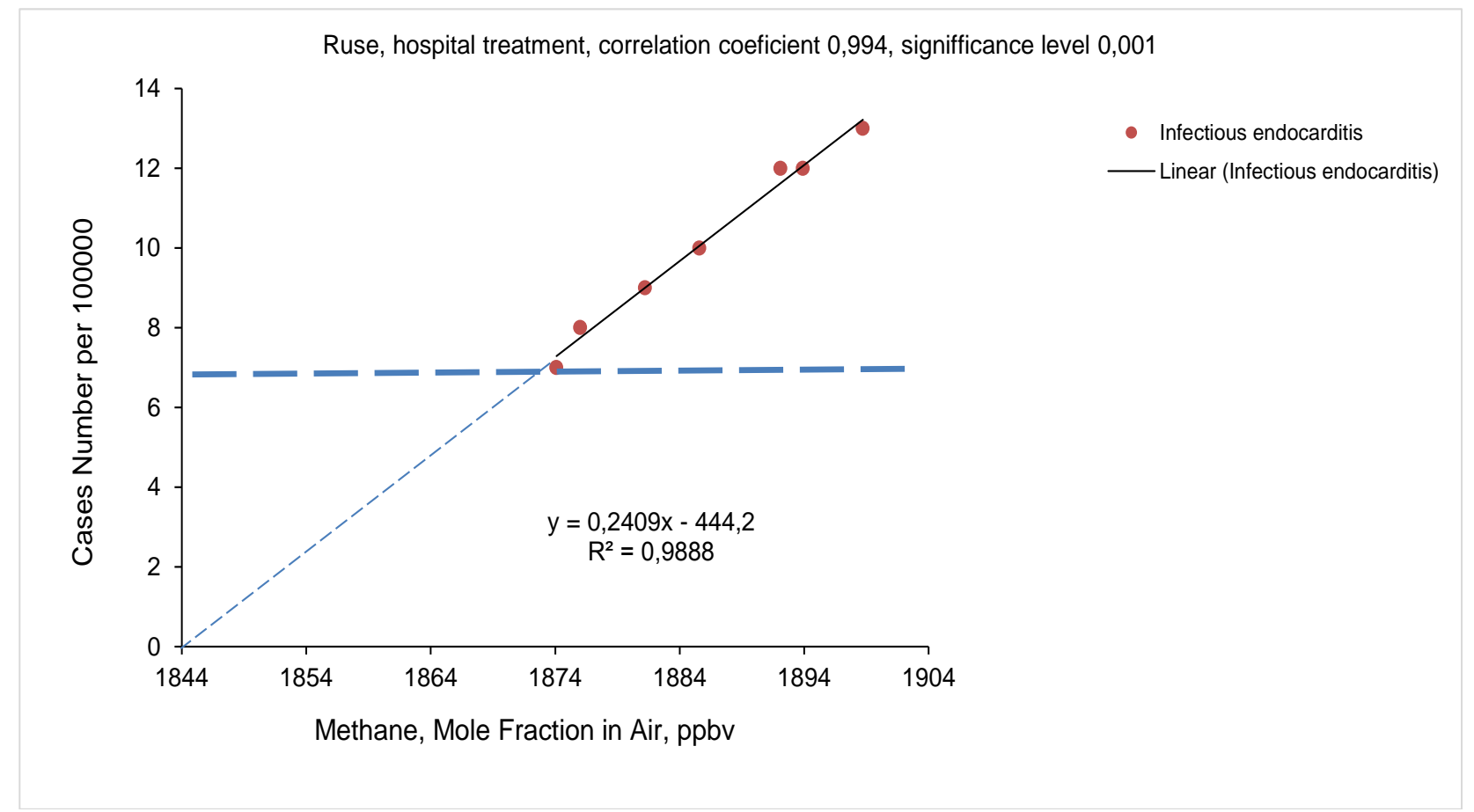

Figure 1. A regression model (line and mathematical expression) of the relationship between the number of clinical pathway 54 "infectious endocarditis" and the relative share of methane in the air.

The continuous straight line denotes the regression model in which an independent variable is a difference between the annual methane content in the air and the smallest of these values. A thick horizontal line is an intercept in a model. A thin line is the continuation of the regression line for methane content values below the minimum annual average for the study years.

The accuracy of the prediction by the regression model reduces beyond the boundaries of the independent variable, so it is not correct for the model to estimate the number of people affected by the pollution outside this interval. In the example of Figure 1 , the range of methane content in the air over Ruse for which the regression model is valid is 1874-1904 ppbv. Due to the increasing error in assessing the number of patients outside these limits, it is not correct to expect the number of patients due to this pollution to become zero if the relative share of methane molecules in the air drops below 1844 ppbv, the value at which the thin broken line crosses the ordinate.

The product between the value of an independent variable in the model and the coefficient before it determines the contribution of this independent variable to the dependent variable. The contribution of each of the pollutants in a particular model was calculated by the average value of its respective independent variable (the abovementioned difference in annual concentration with its minimum). 
The total contribution of all causes was calculated as the sum of the contributions of all pollutants in the model and the intercept.

The ratio of the contribution of a specific pollutant to the overall contribution of all causes of the disease determines the relative contribution of the pollutant to the patient number.

The relative contribution of the pollutant was calculated for each clinical pathway for which the concentration of the pollutant had a statistically significant positive correlation coefficient with the number of treated patients in the district hospitals. If there is more than one pollutant in the regression model, the relative contribution of all the pollutants in the model was calculated as a ratio (between 0 and $100 \%$ ), the numerator of which is the sum of pollutant contributions, and the denominator is the same sum and the intercept in the model.

The number of patients on the clinical pathway due to air pollution was obtained as a product of the relative contribution of the pollutant/pollutants and the total number of patients treated on the clinical pathway.

The cost of hospital care for patients on a particular clinical pathway due to pollutants in the air was calculated as the product of the cost of the clinical pathway multiplied by the number of patients affected by the contamination.
Correlation and regression analysis calculations were performed using the corresponding embedded functions in MS Excel.

\section{RESULTS AND DISCUSSION}

The data included a total of 296 clinical pathways (for 2012). The study included only the 125 clinical pathways for which there had been patients throughout the all 7 years from 2006 to 2012. Of these, 73 have statistically significant positive correlations with air pollutants. There were 52 statistically significant positive correlations between the number of patients on the clinical pathways included in the study and the air pollutant concentrations estimated by satellite data. Accordingly, significant positive correlations were found with the number of patients on 48 clinical pathways with concentrations of air pollutants measured by the ground-based automatic station. No statistically significant correlations of the number of patients treated on the mentioned 73 clinical paths were found with the average annual temperature, atmospheric pressure, relative air humidity, wind speed and direction, the intensity of sunlight.

Two examples of dependencies with a high positive correlation coefficient between the number of patients on a clinical pathway and the pollutant concentrations (Figure 2 and Figure 3) are shown in the figures below.

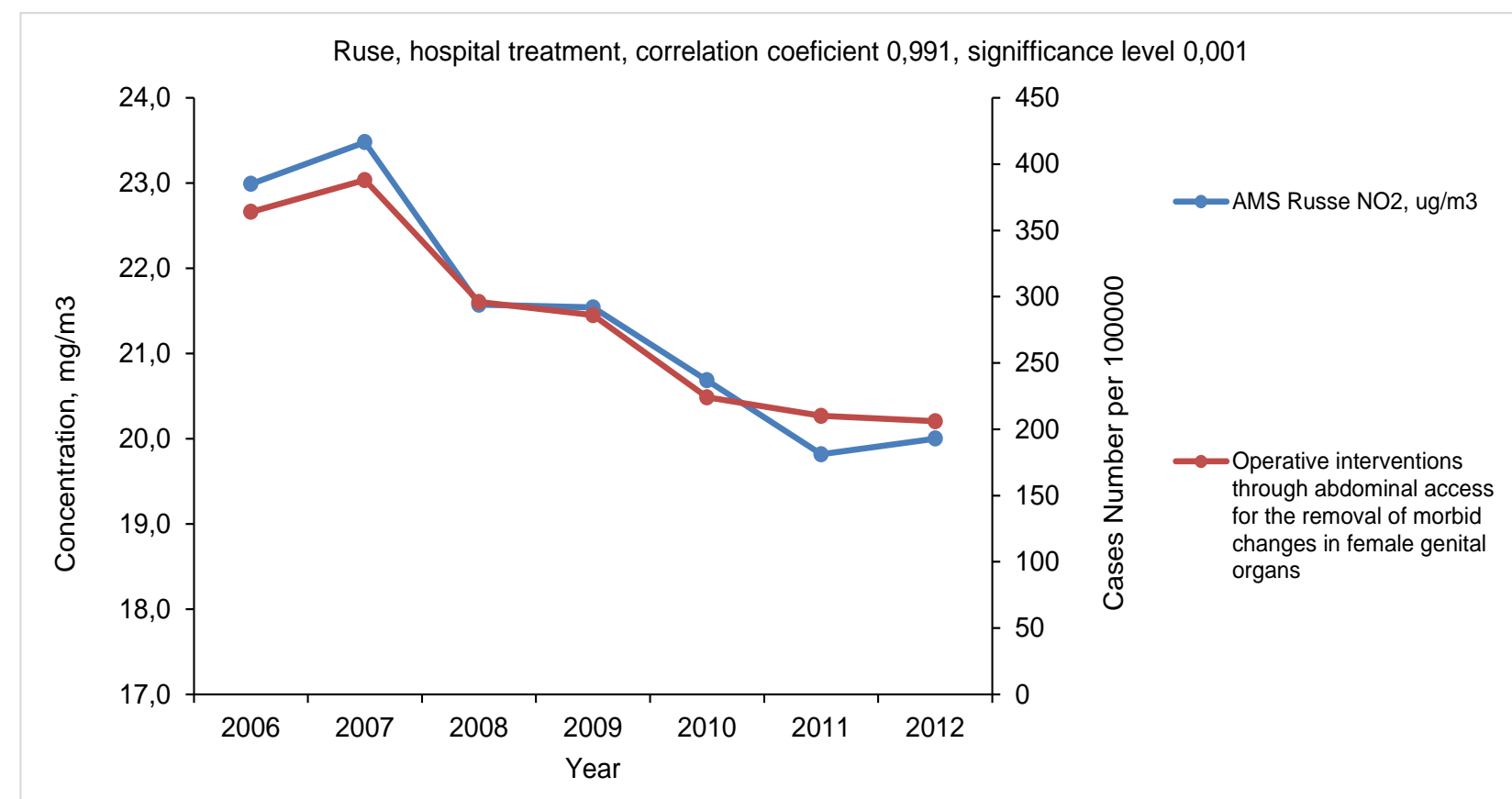

Figure 2. Between the number of surgical interventions through abdominal access for the removal of the female genital tract (147th clinical pathway) in Ruse hospitals and the nitrogen dioxide concentration measured by the Ruse automatic station has a high positive statistically significant correlation. 


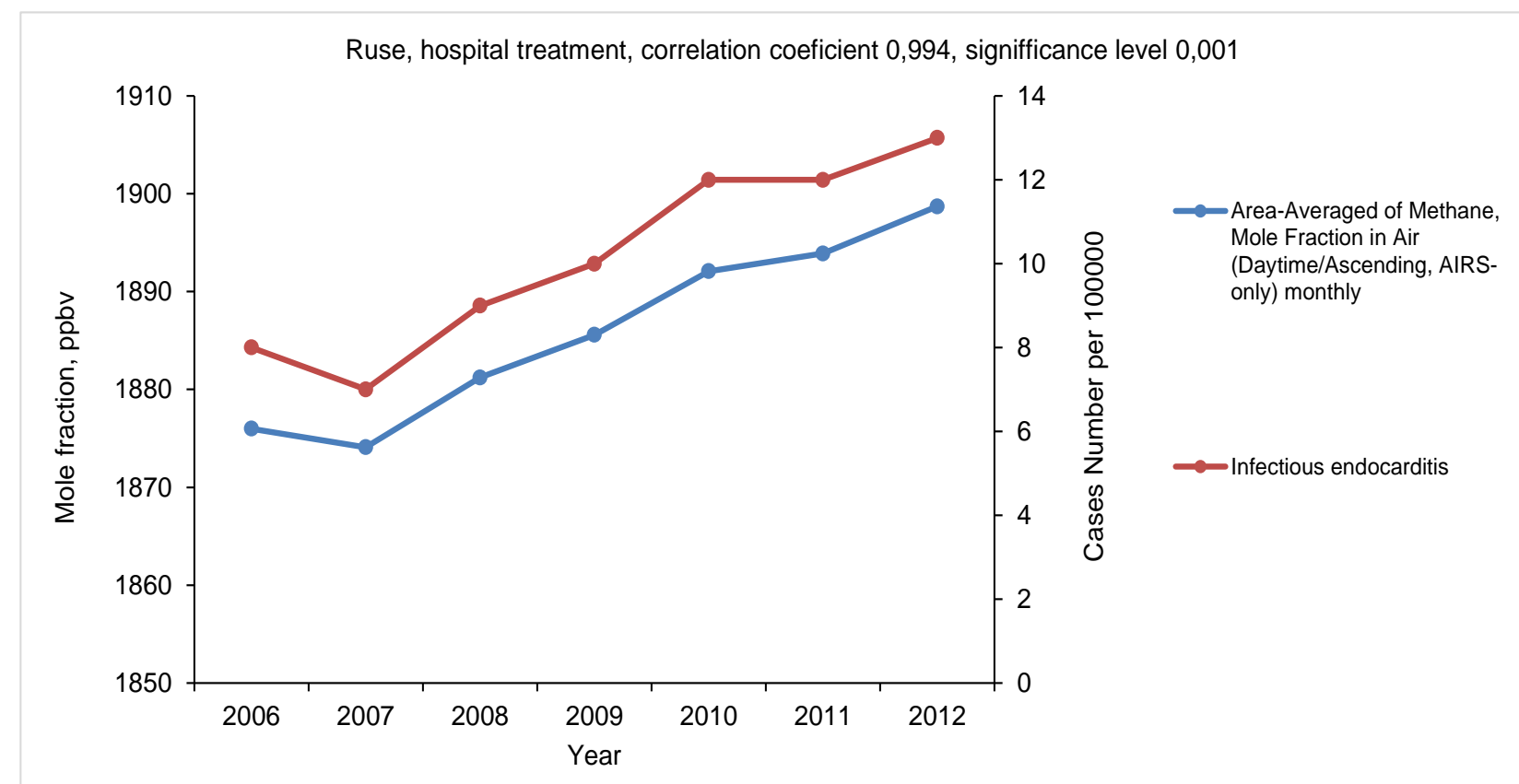

Figure 3. Between the number of patients treated with the diagnosis of "Infectious endocarditis" (54th clinical pathway) in Ruse hospitals and the relative share of methane in the ground atmosphere above Ruse, measured by satellite, there is a high positive statistically significant correlation.

A regression model was developed for each of the clinical pathways for which significant positive correlation/correlations with some of the investigated air pollutants were found. As a dependent variable, the models included the number of patients on the clinical pathway. Independent variables in the models were the differences between the annual concentrations of the pollutants involved and their minimum values over the years in the study. Table 1 gives, by code (nomenclature for 2007, (10)), all clinical pathways (column 1) for which at least one significant positive correlation with air pollutant was found. In columns 2 and 3, the pollutants are measured by satellite and in column 4 - the pollutants measured by the ground-level automatic station, are shown. Column 5 shows the coefficients of determination of the models. In column 6 are shown estimates of the relative contribution of the pollutant/pollutants to the treated on the clinical pathway number of patients. Column 7 shows the average annual number of patients treated on the clinical pathway for the study years. The data in columns 6 and 7 were used to calculate (column 8) the number of patients on the clinical pathway as a result of the influent pollutant/pollutants in the air over Ruse. According to the data in columns 7 and 9 (cost of the clinical pathway), the average annual expenditure on hospital care for all patients treated on the pathway (column 10) was calculated. In column 11 the average annual expenditure on public funds for hospital aid only to those patients affected by the air pollutants, are calculated by the data in columns 8 and 9.

According to the data from columns 7 and 8 of Table 1 it can be calculated that of the average number of 17403 patients treated on the clinical pathways, 4716 , i.e. $27 \%$ were affected by air pollution. For their treatment, $31 \%$ of the means for the treatment of all patients on the clinical paths with the influence of the pollutants were spent.

An average of 31025 patients was treated per year on the 125 clinical pathways included in the study. The number affected by air pollution patients is 4716 ( $15 \%$ of the average number). On average, over the years of the study, NHIF Rousse paid for hospital treatment per year for 47695 patients. Assuming the same relative share $(15 \%)$ for the air pollution impact of all patients who received hospital aid in the hospitals in the district of Ruse, it can be calculated that the air pollution affects an average of 7255 patients per year. 
TAKUCHEV N., et al.

Table 1. Clinical pathways, number of patients influenced by the studied air pollutants over Ruse,

types of pollutants, number of people affected by air pollution, public costs related to pollution.

\begin{tabular}{|c|c|c|c|c|c|c|c|c|c|c|}
\hline 1 & 2 & 3 & 4 & 5 & 6 & 7 & 8 & 9 & 10 & 11 \\
\hline 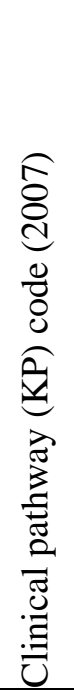 & 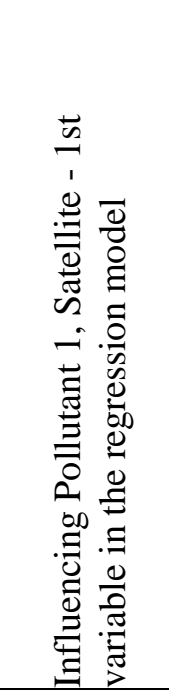 & 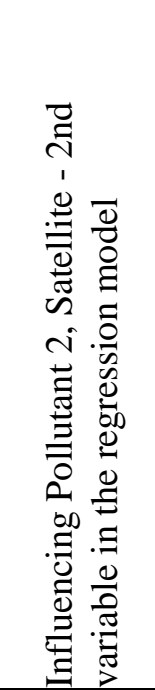 & 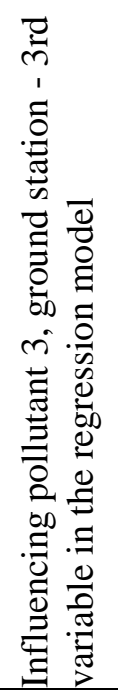 & 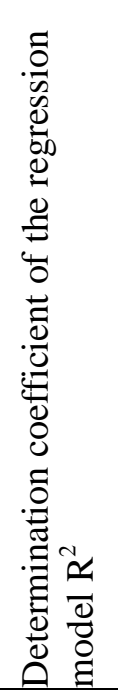 & 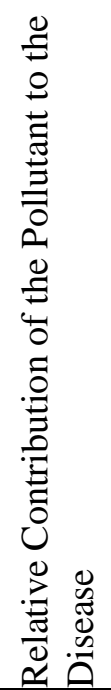 & 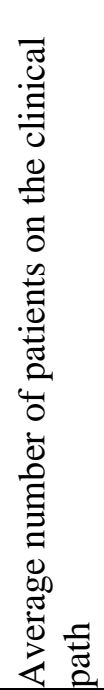 & 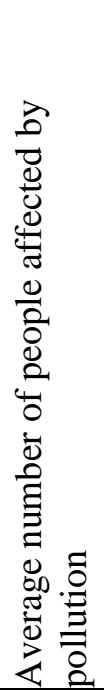 & $\begin{array}{l}\hat{8} \\
0 \\
0 \\
0 \\
0 \\
0 \\
0 \\
0 \\
0 \\
0 \\
0\end{array}$ & 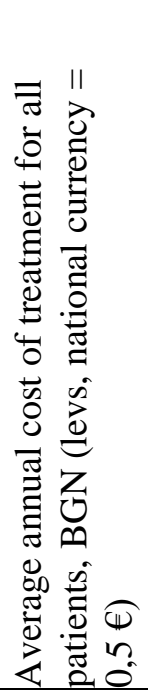 & 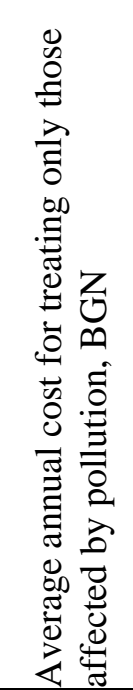 \\
\hline 3 & & & $\mathrm{NO}_{2}$ & 0,861 & $8 \%$ & 156 & 13 & 700 & 109200 & 8959 \\
\hline 7 & Methane & & $\mathrm{PM}_{10}$ & 0,933 & $63 \%$ & 429 & 271 & 462 & 198000 & 125092 \\
\hline 9 & $\mathrm{SO}_{2}$ & & & 0,761 & $42 \%$ & 18 & 7 & 1560 & 27634 & 11594 \\
\hline 18 & & & $\mathrm{SO}_{2}$ & 0,623 & $6 \%$ & 137 & 8 & 210 & 28800 & 1589 \\
\hline 26 & & & $\mathrm{O}_{3}$ & 0,770 & $26 \%$ & 455 & 117 & 642 & 292202 & 75416 \\
\hline 30 & & & $\mathrm{NO}_{2}$ & 0,929 & $49 \%$ & 289 & 143 & 600 & 173657 & 85908 \\
\hline 31 & Methane & $\mathrm{CO}$ & $\mathrm{PM}_{10}$ & 0,924 & $27 \%$ & 400 & 108 & 500 & 200071 & 53863 \\
\hline 33 & Methane & & & 0,714 & $23 \%$ & 204 & 47 & 1010 & 206473 & 47542 \\
\hline 38 & Methane & & $\mathrm{PM}_{10}$ & 0,956 & $79 \%$ & 318 & 252 & 900 & 286457 & 226801 \\
\hline 50 & Methane & & & 0,760 & $49 \%$ & 135 & 66 & 2500 & 337143 & 166062 \\
\hline 54 & Methane & & $\mathrm{PM}_{10}$ & 0,995 & $28 \%$ & 10 & 3 & 2200 & 22314 & 6215 \\
\hline 55 & Methane & & & 0,727 & $36 \%$ & 54 & 19 & 420 & 22500 & 8074 \\
\hline 59 & $\mathrm{SO}_{4}$ & & & 0,888 & $17 \%$ & 44 & 8 & 605 & 26361 & 4545 \\
\hline 66 & Methane & Aerosol & $\mathrm{PM}_{10}$ & 0,963 & $96 \%$ & 20 & 19 & 525 & 10425 & 10039 \\
\hline 68 & Aerosol & & & 0,615 & $14 \%$ & 161 & 23 & 300 & 48429 & 7016 \\
\hline 70 & Methane & & $\mathrm{C}_{6} \mathrm{H}_{6}$ & 0,896 & $55 \%$ & 67 & 37 & 515 & 34652 & 19118 \\
\hline 73 & & & $\mathrm{NO}_{2}$ & 0,664 & $30 \%$ & 59 & 18 & 630 & 37170 & 11299 \\
\hline 74 & & & $\mathrm{SO}_{2}$ & 0,785 & $51 \%$ & 164 & 84 & 105 & 17220 & 8788 \\
\hline 76 & Methane & $\begin{array}{c}\text { Black } \\
\text { carbon }\end{array}$ & $\mathrm{PM}_{10}$ & 0,985 & $100 \%$ & 137 & 137 & 788 & 108069 & 108069 \\
\hline 81 & & & $\mathrm{C}_{6} \mathrm{H}_{6}$ & 0,756 & $29 \%$ & 4 & 1 & 556 & 2145 & 629 \\
\hline 83 & & & $\mathrm{SO}_{2}$ & 0,642 & $11 \%$ & 310 & 34 & 368 & 114027 & 12642 \\
\hline 91 & Methane & & & 0,778 & $6 \%$ & 1608 & 101 & 350 & 562850 & 35184 \\
\hline 92 & & & $\mathrm{NO}_{2}$ & 0,572 & $11 \%$ & 187 & 20 & 378 & 70578 & 7578 \\
\hline 95 & $\mathrm{O}_{3}$ & & & 0,736 & $30 \%$ & 457 & 136 & 231 & 105534 & 31443 \\
\hline 96 & Methane & & & 0,816 & $56 \%$ & 53 & 29 & 605 & 31892 & 17744 \\
\hline 116 & Methane & & & 0,611 & $23 \%$ & 426 & 100 & 303 & 129121 & 30233 \\
\hline 121 & & & $\mathrm{C}_{6} \mathrm{H}_{6}$ & 0,668 & $16 \%$ & 52 & 8 & 490 & 25620 & 4063 \\
\hline 123 & & & $\mathrm{NO}_{2}$ & 0,625 & $30 \%$ & 217 & 64 & 250 & 54143 & 16082 \\
\hline 130 & & & $\mathrm{NO}_{2}$ & 0,747 & $63 \%$ & 6 & 4 & 1265 & 7409 & 4693 \\
\hline 141 & $\mathrm{O}_{3}$ & & & 0,774 & $12 \%$ & 1592 & 188 & 400 & 636629 & 75078 \\
\hline 142 & & & $\mathrm{NO}_{2}$ & 0,867 & $20 \%$ & 650 & 127 & 158 & 102723 & 20045 \\
\hline 143 & & & $\mathrm{SO}_{2}$ & 0,690 & $53 \%$ & 286 & 151 & 810 & 232007 & 122113 \\
\hline 145 & & & $\mathrm{NO}_{2}$ & 0,779 & $18 \%$ & 249 & 45 & 788 & 196437 & 35301 \\
\hline
\end{tabular}


TAKUCHEV N., et al.

\begin{tabular}{|c|c|c|c|c|c|c|c|c|c|c|}
\hline 146 & & & $\mathrm{NO}_{2}$ & 0,650 & $21 \%$ & 67 & 14 & 810 & 53923 & 11560 \\
\hline 147 & & & $\mathrm{NO}_{2}$ & 0,983 & $30 \%$ & 282 & 84 & 525 & 148050 & 44238 \\
\hline 149 & & & $\mathrm{NO}_{2}$ & 0,876 & $11 \%$ & 1124 & 126 & 452 & 508177 & 56958 \\
\hline 150 & & & $\mathrm{NO}_{2}$ & 0,626 & $23 \%$ & 69 & 16 & 452 & 31059 & 7286 \\
\hline 160 & Methane & & & 0,750 & $14 \%$ & 191 & 27 & 2000 & 382571 & 54730 \\
\hline 165 & $\mathrm{O}_{3}$ & & & 0,711 & $25 \%$ & 19 & 5 & 567 & 10530 & 2640 \\
\hline 168 & $\mathrm{CO}$ & & & 0,588 & $12 \%$ & 98 & 12 & 546 & 53664 & 6697 \\
\hline 169 & & & $\mathrm{NO}_{2}$ & 0,735 & $24 \%$ & 70 & 17 & 780 & 54934 & 13240 \\
\hline 172 & $\mathrm{SO}_{2}$ & & & 0,662 & $51 \%$ & 13 & 6 & 2226 & 27984 & 14329 \\
\hline 173 & $\mathrm{SO}_{2}$ & & & 0,721 & $64 \%$ & 6 & 4 & 880 & 5154 & 3319 \\
\hline 178 & & & $\mathrm{NO}_{2}$ & 0,708 & $30 \%$ & 91 & 27 & 561 & 51051 & 15319 \\
\hline 179 & Methane & & $\mathrm{C}_{6} \mathrm{H}_{6}$ & 0,968 & $11 \%$ & 150 & 16 & 746 & 111687 & 11934 \\
\hline 180 & & & $\mathrm{NO}_{2}$ & 0,726 & $18 \%$ & 290 & 51 & 209 & 60700 & 10681 \\
\hline 181 & Methane & Aerosol & & 0,975 & $66 \%$ & 85 & 56 & 1800 & 152486 & 101348 \\
\hline 185 & Aerosol & & & 0,759 & $75 \%$ & 152 & 114 & 352 & 53605 & 40205 \\
\hline 190 & Methane & & $\mathrm{PM}_{10}$ & 0,972 & $45 \%$ & 78 & 35 & 3318 & 258330 & 115510 \\
\hline 191 & Methane & & $\mathrm{C}_{6} \mathrm{H}_{6}$ & 0,873 & $50 \%$ & 82 & 41 & 1710 & 140709 & 70108 \\
\hline 202 & Methane & & $\mathrm{C}_{6} \mathrm{H}_{6}$ & 0,875 & $8 \%$ & 893 & 75 & 315 & 281340 & 23779 \\
\hline 205 & $\begin{array}{c}\text { Black } \\
\text { carbon }\end{array}$ & & & 0,659 & $45 \%$ & 105 & 47 & 1656 & 173880 & 77881 \\
\hline 216 & Methane & & $\mathrm{PM}_{10}$ & 0,859 & $30 \%$ & 79 & 24 & 1200 & 94800 & 28826 \\
\hline 219 & Methane & & & 0,679 & $36 \%$ & 58 & 21 & 610 & 35206 & 12734 \\
\hline 222 & & & $\mathrm{NO}_{2}$ & 0,787 & $20 \%$ & 461 & 93 & 400 & 184400 & 37276 \\
\hline 223 & & & $\mathrm{SO}_{2}$ & 0,797 & $9 \%$ & 422 & 40 & 250 & 105500 & 9911 \\
\hline 228 & Methane & $\begin{array}{l}\text { Black } \\
\text { carbon }\end{array}$ & $\mathrm{PM}_{10}$ & 0,938 & $28 \%$ & 60 & 17 & 330 & 19894 & 5516 \\
\hline 229 & Methane & & $\mathrm{PM}_{10}$ & 0,970 & $58 \%$ & 9 & 5 & 330 & 2923 & 1692 \\
\hline 230 & $\mathrm{O}_{3}$ & & & 0,676 & $69 \%$ & 18 & 12 & 788 & 13846 & 9619 \\
\hline 231 & & & $\mathrm{NO}_{2}$ & 0,847 & $57 \%$ & 12 & 7 & 825 & 10136 & 5766 \\
\hline 241 & $\mathrm{CO}$ & & $\mathrm{PM}_{10}$ & 0,909 & $13 \%$ & 652 & 86 & 263 & 171514 & 22672 \\
\hline 243 & $\mathrm{O}_{3}$ & & & 0,613 & $53 \%$ & 15 & 8 & 263 & 3907 & 2052 \\
\hline 244 & Methane & Aerosol & & 0,965 & $62 \%$ & 1423 & 881 & 263 & 374211 & 231767 \\
\hline 253 & Methane & $\begin{array}{l}\text { Black } \\
\text { carbon }\end{array}$ & $\mathrm{PM}_{10}$ & 0,967 & $35 \%$ & 213 & 74 & 600 & 127886 & 44557 \\
\hline 268 & Methane & & $\mathrm{C}_{6} \mathrm{H}_{6}$ & 0,952 & $84 \%$ & 16 & 13 & 2894 & 46304 & 38694 \\
\hline 269 & & & $\mathrm{SO}_{2}$ & 0,835 & $32 \%$ & 60 & 19 & 650 & 38721 & 12441 \\
\hline 272 & & & $\mathrm{SO}_{2}$ & 0,722 & $60 \%$ & 122 & 74 & 800 & 97943 & 58945 \\
\hline 275 & & & $\mathrm{SO}_{2}$ & 0,825 & $54 \%$ & 6 & 3 & 1500 & 9214 & 4979 \\
\hline 280 & & & $\mathrm{SO}_{2}$ & 0,837 & $13 \%$ & 158 & 20 & 263 & 41629 & 5219 \\
\hline 283 & PM & $\mathrm{PM}_{2,5}$ & & 0,885 & $91 \%$ & 4 & 3 & 263 & 977 & 891 \\
\hline 286 & Methane & & & 0,599 & $69 \%$ & 47 & 33 & 357 & 16881 & 11730 \\
\hline 288 & Methane & & $\mathrm{PM}_{10}$ & 0,928 & $30 \%$ & 163 & 49 & 667 & 108912 & 32501 \\
\hline 291 & Methane & & $\mathrm{C}_{6} \mathrm{H}_{6}$ & 0,985 & $39 \%$ & 186 & 73 & 420 & 78300 & 30570 \\
\hline \multicolumn{6}{|c|}{ Total: } & 17403 & 4716 & & 8600830 & 2688937 \\
\hline
\end{tabular}

For the years of the study, at the prices of the clinical pathways for 2007 (10), the average cost for the treatment of the patients on the 125 clinical paths included in the study was BGN 15681358 , of which BGN 2688937, i.e. $17 \%$, are the costs of treating the patients as a result of air pollution over Ruse. The estimated cost of funds on a clinical path for one patient due to air pollution is 2688937 BGN / 4716 patients $=570 \mathrm{BGN}$.

In particular, in 2007 NHIF Ruse paid for treatment of 45475 patients on all clinical paths (11). If $15 \%$ (6821 patients) of them 
have been hospitalized as a consequence of the pollution, NHIF Rousse has paid to the hospitals in the area due to the pollution BGN 3886822 .

For 2017 for hospital medical aid RHIF Ruse paid 54872579 BGN (11). If the relative share of the cost of hospital care for patients affected by the pollution is $17 \%$ as in 2007 , the amount spent for hospital treatment of patients due to the pollution of Ruse is BGN 9328338, i.e. for 10 years, it has grown 2,5 times.

For each of the air pollutants, it can be calculated: the number of clinical pathways on
TAKUCHEV N., et al. which they affect (Table 1), the number of hospital patients due to the pollutant and the consumption of public funds related to the hospital treatment due to the pollutant. It can be seen (Table 2) that the methane and fine particles with aerodynamic diameter $10 \mu \mathrm{m}$, aerosols and soot have the greatest negative impact on the health of the patients treated in hospitals in the Ruse district between 2006 and 2012. Nitrogen and sulfur dioxides have an intermediate negative impact on the health of hospitalized patients. Benzene, ozone, and carbon monoxide have a weak detrimental impact.

Table 2. Air pollutants above Ruse, number of people affected and treated in the hospital as a result of air pollution, public costs related to pollution.

\begin{tabular}{|c|c|c|c|}
\hline 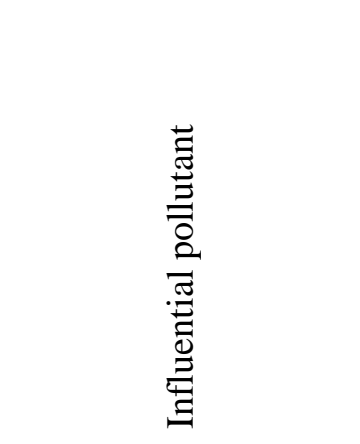 & 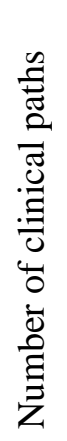 & 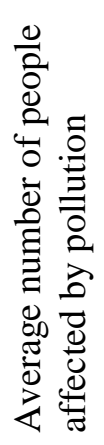 & 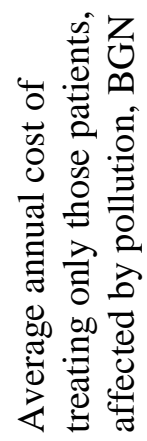 \\
\hline Methane & 29 & 2630 & 1670033 \\
\hline Aerosol & 5 & 1094 & 390374 \\
\hline $\mathrm{PM}_{10}$ & 13 & 1079 & 781353 \\
\hline $\mathrm{NO}_{2}$ & 17 & 870 & 392188 \\
\hline $\mathrm{O}_{3}$ & 6 & 466 & 196248 \\
\hline $\mathrm{SO}_{2}$ & 12 & 450 & 236628 \\
\hline Black carbon (сажди) & 4 & 275 & 236023 \\
\hline $\mathrm{C}_{6} \mathrm{H}_{6}$ & 8 & 265 & 198895 \\
\hline $\mathrm{CO}$ & 3 & 206 & 83232 \\
\hline $\mathrm{SO} 4$ & 1 & 8 & 4545 \\
\hline PM2,5 & 1 & 3 & 891 \\
\hline
\end{tabular}

The mixtures of pollutants also have a negative impact on the health of patients treated in the hospitals of the district of Ruse. The main component is methane, which is mainly combined with $\mathrm{PM}_{10}$, soot, aerosols and benzene.

\section{CONCLUSIONS}

The study showed that the inpatient morbidity of a number of illnesses in the Ruse area was influenced by air pollution over the city.

The study has shown that combined groundbased and satellite air pollution monitoring is a reliable source of air pollution information and may even be a source of information for the public expenditure for the treatment of air pollution-related diseases.

The study assessed the relation of air pollutants over Ruse to the number of patients treated in Ruse hospitals and on this basis estimated the public costs of hospital care due to air pollution.

\section{REFERENCES}

1. Ruse Bulgaria coordinates. https://tools.wmflabs.org/geohack/geohack. php?pagename $=$ Ruse,, Bulgaria $\&$ params $=4$ 3_49_23_N_25_57_14_E_region:BG_type: city , 4/12/2018.

2. The population of Ruse District (http://ruse.bg/naselenie), 4/12/2018. 
3. NASA site with data from satellite observations of ground air quality. https://giovanni.gsfc.nasa.gov 13.4.2018 г.

4. Orbits.

(https://earthobservatory.nasa.gov/Features/ OrbitsCatalog/page2.php )4/17/2018

5. Terra. (https://terra.nasa.gov/about) 4/17/2018

6. Pawan K. Bhartia(2012), OMI/Aura TOMS-Like Ozone, Aerosol Index, Cloud Radiance Fraction L3 1 day 1 degree x 1 degree V3, NASA Goddard Space Flight Center, Goddard Earth Sciences Data and Information Services Center (GES DISC), Accessed [4/17/2018] 10.5067 /Aura/ OMI /DATA3001

7. Global Modeling and Assimilation Office (GMAO)(2015), tavgM_2d_aer_Nx: 2d,Monthly mean, Time-averaged, SingleLevel,Assimilation,Aerosol Diagnostics V5.12.4, Greenbelt, MD, USA, Goddard Earth Sciences Data and Information Services Center (GES DISC),
TAKUCHEV N., et al. Accessed 4/17/2018 10.5067/FH9A0MLJP C7N

8. AIRS Science Team/Joao Texeira(2013), AIRS/Aqua L3 Daily Standard Physical Retrieval (AIRS+AMSU) 1 degree x 1 degree V006, Greenbelt, MD, USA, Goddard Earth Sciences Data and Information Services Center (GES DISC), Accessed [Data Access Date] doi:10.5067/Aqua/AIRS/DATA301

9. Global Modeling and Assimilation Office (GMAO)(2015a), MERRA-2 tavgM_2d_chm_Nx: 2d,Monthly mean, Time-Averaged, Single-Level, Assimilation, Carbon Monoxide and Ozone Diagnostics V5.12.4, Greenbelt, MD, USA, Goddard Earth Sciences Data and Information Services Center (GES DISC), Accessed $4 / 17 / 2018$ 10.5067/WMT31RKEXK8I

10.NHIF, National Framework Contract 2007, Section V, "Prices, terms and procedure for payment for hospital care")

11.Payments RHIF Rousse, 2017. https://www.nhif.bg/page/216 4/17/2018 